\title{
Salvage prostatectomy for post-radiation adenocarcinoma with treatment effect: Pathological and oncological outcomes
}

\author{
Michael J. Metcalfe, MD'; Patricia Troncoso, MD²; Charles C. Guo, MD'; Hsiang-Chun Chen, MD; \\ Yasar Bozkurt, MD'; John F. Ward, MD'; Louis L. Pisters, $M D^{\prime}$
}

Department of Urology; ${ }^{2}$ Department of Pathology; ${ }^{3}$ Department of Biostatistics; University of Texas MD Anderson Cancer Centre, Houston, TX, United States

Cite as: Can Urol Assoc J 2017;11 (7):E277-84. http://dx.doi.org/10.5489/cuaj.4304

Published online July 11, 2017

\section{Abstract}

Introduction: Prostate biopsies following localized radiation therapy for prostate cancer often demonstrate residual prostatic carcinoma with treatment effect (CTE). The final oncological outcome of prostatic CTE is currently uncertain. We studied the pathological and oncological outcomes for a large cohort of patients who had CTE on post-radiation therapy biopsy and subsequently underwent salvage radical prostatectomy (SRP).

Methods: A single-centre retrospective review of all SRPs performed from 1995-2014 was performed. Cases were selected for this analysis if they had had a post-radiation "for-cause" biopsy. Biopsy results were compared to final pathology results following SRP. Pathological and clinical outcomes were compared by extent of treatment effect seen on the post-radiation biopsy.

Results: A total of 70 patients who had salvage prostatectomy at MD Anderson Cancer Centre from 2007-2015 met study criteria. CTE was found on biopsy in the absence of other adenocarcinoma in 16 patients. Among them, one (7\%) patient had no evidence of carcinoma at the time of salvage prostatectomy, four $(27 \%)$ had CTE, three $(20 \%)$ had adenocarcinoma with minimal or partial treatment effect (PTE), and seven (47\%) had adenocarcinoma with no treatment effect (NTE). For those with CTE on biopsy, 69\% had biochemical recurrence at a median time of 0.4 years (interquartile range [IQR] 0.22-1.52) vs. 52\% for all patients (median 0.44 years, IQR $0.11-1.70$ ) and $47 \%$ for those with no treatment effect (median 0.62 years, IQR 0.05-1.90). Metastasis developed after salvage prostatectomy in $11.8 \%$ of the whole cohort $(8 / 68$, median time to metastasis was 3.03 years, IQR 2.45-4.47), 26.7\% of patients with CTE (median 3.2 years, IQR 1.96-4.44), and 6.7\% of patients with NTE (median 2.45 years, IQR 0.98-2.86). Median recurrence-free survival was 2.78 years $(95 \%$ confidence interval $[\mathrm{Cl}] 0.84-5.43)$ for all patients, 0.51 years $(95 \% \mathrm{Cl} 0.22-2.35)$ for those with CTE, and 4.95 years $(95 \% \mathrm{Cl} 0.95-7.08)$ for those with NTE; the difference was not significant $(p=0.13)$. On multivariate analysis, pre-SRP biopsy Gleason grade $<7$ (hazard ratio [HR] 0.38; $95 \% \mathrm{Cl} 0.14-1.02)$ and number of biopsy cores positive for carcinoma (HR 1.11; 95\% Cl 1.00-1.22) were significant for prediction of cancer recurrence.
Conclusions: Patients undergoing salvage prostatectomy for CTE or PTE demonstrated in a for-cause biopsy after radiation therapy had pathological evidence of viable, untreated cancer in more than $50 \%$ of cases and were at significant risk of adverse pathological features. Patients with CTE may therefore benefit from salvage radical prostatectomy. Our study is limited by its retrospective nature and sample size. More studies are required to further validate our findings and assess the benefit of SRP in this population.

\section{Introduction}

Although radiation therapy (RT) remains a popular treatment for prostate cancer, biochemical relapse occurs in up to $25-60 \%$ of patients, depending on disease stage. Prostate biopsy remains the gold standard means of assessment of local control, and a positive biopsy is required before salvage local therapy is considered. Assessment of prostate biopsies after RT can be challenging for pathologists because radiation-induced changes and histological atypia in benign glands may mimic carcinoma. Post-radiation prostate biopsies can be classified by the presence or absence of malignant cells and the presence or absence of treatment effect. ${ }^{1-5}$

Patients with obvious malignant cells and no evidence of radiation effect on biopsy have indisputable local recurrence and are obvious candidates for salvage local therapies. However, it is controversial whether patients with biochemical relapse who are demonstrated to have cancer cells with radiation treatment effect (CTE) on biopsy should be considered to have local recurrence. These patients may be considerably different from those who are shown to have CTE on routine biopsies obtained after radiation. There is a paucity of data evaluating whether CTE seen on "for-cause" biopsies is biologically active and a threat to the patient. At MD Anderson, we have considered these patients to have local recurrence and have offered them salvage local therapies. The objective of our study was to evaluate the pathological and oncological outcomes for patients with CTE on 
Metcalfe et al.

post-RT biopsy who subsequently underwent salvage radical prostatectomy (SRP).

\section{Methods}

Following institutional review board approval (RCR030847), we reviewed the Department of Urology database to identify all patients who underwent a radical prostatectomy at MD Anderson Cancer Centre from 1995-2015. Patients who underwent localized RT, had biochemical or biopsyproven failure, and then underwent SRP were included in the study. All patients had to have had a "for-cause" biopsy (as opposed to a routine post-RT biopsy) within six months of SRP. Only patients whose biopsy pathology report mentioned the presence of treatment effect at any point in the report were included in the study. Although workup was not standardized, all patients who underwent a SRP had had a full history, physical exam, lab work, and imaging. The assessment included performance status, prostate-specific antigen (PSA) test, and axial imaging of the chest and abdomen (most commonly via computed tomography [CT] with contrast), as well as a bone scan. Patients were excluded from the study if their final pathology showed histology other than adenocarcinoma of the prostate or if they had distant metastasis. All patients had been reviewed by a multidisciplinary clinic prior to the decision to perform surgery.

Patient demographic, clinical, and pathological information was collected from chart review and the online electronic medical records (EMR). Followup information was gathered from the online EMR. For patients who did not follow up at MD Anderson, an institutional annual mail-in survey was sent to patients to gather followup information, specifically disease recurrence, adjunctive therapies, and details of death.

All patients had a pathology review done at MD Anderson. For partial treatment effect (PTE), patients' biopsy results were classified as: 1) benign gland with treatment effect (Fig. 1A); 2) $\mathrm{CTE}$, where all cancerous glands had to show treatment effect (Fig. 1B); 3) adenocarcinoma with minimal or PTE in which some cancerous glands showed treatment effect, while others did not (Fig. 1C); and 4) adenocarcinoma with no treatment effect (NTE) (Fig. 1D). Non-neoplastic or benign prostatic glands with treatment effect were characterized by small atrophic glands with irregular lumens and marked reactive nuclear atypia (Fig. 1A). In contrast, prostatic CTE presented as small bland glands or single cells with relatively uniform pyknotic nuclei and abundant cytoplasm (Fig. 1B). A Gleason score was given only to the prostatic adenocarcinomas that did not show any treatment effect (Fig. 1D). The final pathology from the SRP specimen was compared to the pathology from the biopsy using the same four categories.

The primary outcome of interest was the proportion of patients with viable disease on final pathology, as defined by adenocarcinoma without treatment effect. Secondary

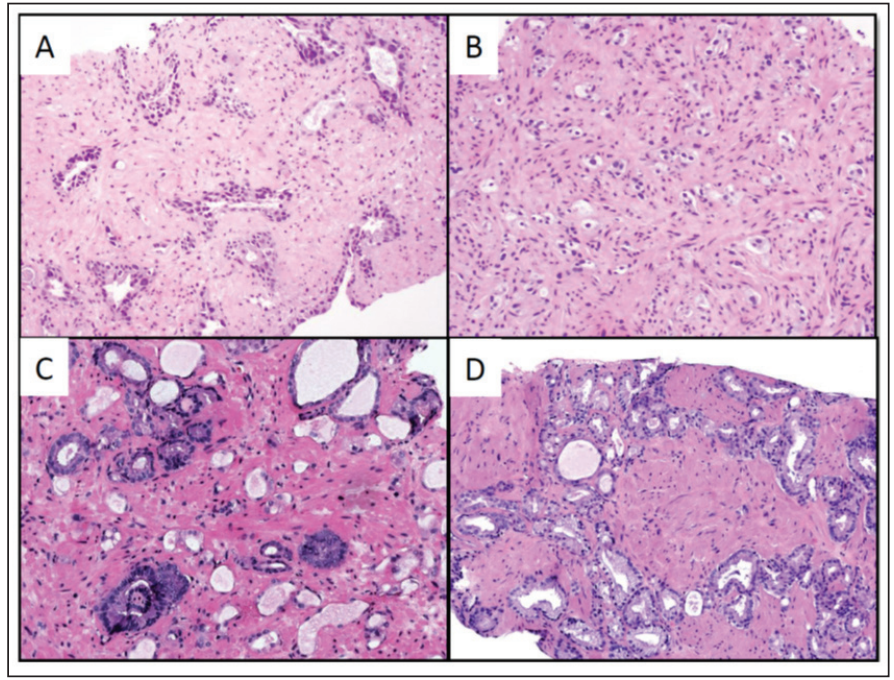

Fig. 1. Effect of radiation treatment on the prostate from a patient in our cohort. (A) Non-neoplastic glands with treatment effect showed glandular atrophy and marked reactive nuclear atypia; $(\boldsymbol{B})$ adenocarcinoma with treatment effect showed small glands or single cells with pyknotic nuclei and abundant cytoplasm; (C) adenocarcinoma with partial treatment effect; and (D) adenocarcinoma with no treatment effect.

outcomes included post-SRP PSA nadir, biochemical recurrence (BCR), use of hormonal therapy after SRP, development of androgen independence, metastasis-free survival, overall survival (OS), and cancer-specific survival (CSS).

Patient characteristics were tabulated by the treatment effect in the highest-risk location at the time of pre-SRP biopsy. The differences in patient characteristics were compared using Kruskal-Wallis tests, Fisher exact tests, or chisquare tests, as appropriate. OS was defined as the time interval between salvage prostatectomy and death and was censored at the last followup date for patients who were alive. Recurrence-free survival (RFS) was defined as the time interval between surgery date and BCR date or death date, whichever came first, and was censored at last followup date for patients who were alive without recurrence. BCR was defined using the ASTRO definition: a rise by $2 \mathrm{ng} / \mathrm{mL}$ or more above the PSA nadir. ${ }^{6}$ The probabilities of OS and RFS were estimated using the Kaplan-Meier method. ${ }^{7}$ Univariate and multivariate Cox proportional hazards regression models were used to assess the association between patient characteristics and OS or RFS. Statistical analyses were performed using SAS 9.3 (The SAS Institute, Cary, NC, U.S.) and S-PLUS (TIBCO Corporation, Palo Alto, CA, U.S.). ${ }^{8}$

\section{Results}

\section{Baseline characteristics}

A total of 88 patients underwent salvage prostatectomy at MD Anderson between 1995 and 2015 because of failure of 
disease control following local radiotherapy. We excluded 18 patients from the study: four patients who underwent prostatectomy for a cause other than local control, five who did not have a biopsy pathology re-review done at MD Anderson, two who had squamous cell carcinoma, and seven whose biopsy pathology reports did not mention treatment effect or stated that there was a lack of treatment effect. A total of 70 patients who underwent salvage prostatectomy between June 2007 and March 2015 were included in this study.

Pre-SRP biopsy results for the 70 patients were as follows: $45(64.3 \%)$ had adenocarcinoma with no evidence of treatment effect, nine $(12.9 \%)$ had carcinoma with partial treatment effect, and $16(22.9 \%)$ had carcinoma with treatment effect as the highest-risk foci on biopsy.

Demographic and clinical data for all patients who underwent salvage prostatectomy, characterized by pre-SRP biopsy treatment effect group, are listed in Table 1. The patients who had CTE on pre-SRP biopsy had similar demographic features and had similar distributions of PSA level, stage, and Gleason score at initial diagnosis of prostate cancer when compared with those in other treatment effect groups. The median age was 60.2 years (interquartile range [IQR] 54.4-64.6). The median PSA level at diagnosis was $5.9 \mathrm{ng} /$ $\mathrm{ml}$ (IQR 4.7-11.9). The median time from treatment to PSA nadir was 1.9 years (IQR 0.9-2.9), with a median PSA nadir of $0.5 \mathrm{ng} / \mathrm{ml}$ (IQR 0.2-1.1). Of the 70 patients, 66 met had BCR following RT prior to the post-RT biopsy. At diagnosis, 16 patients $(22.8 \%)$ had had a Gleason grade of less than 7 , $39(55 \%)$ had had a Gleason grade of 7, and $10(14.2 \%)$ had had a Gleason grade of $>7$. For clinical stage, eight patients $(11.4 \%)$ had cT3 disease and no patients had cT4 disease.

Forty-two patients $(60 \%)$ received external beam radiation therapy (EBRT), $14(20 \%)$ received brachytherapy therapy, six $(9 \%)$ received proton beam, and eight $(11 \%)$ received EBRT with brachytherapy boost; there was no significant difference in amount of treatment effect for RT delivery method $(p<0.05)$. Two patients $(3 \%)$ received chemotherapy prior to their salvage biopsy; both of these demonstrated NTE. The majority of patients, $22(31 \%)$, received prior androgendeprivation therapy through their initial treatment course of radiation (27\% in NTE, $56 \%$ in $\mathrm{PTE}$, and $31 \%$ in CTE). Only four patients had adjunct salvage therapies prior to SRP: one had cryotherapy, then EBRT; two had EBRT, then cryotherapy; and one had systemic chemotherapy.

\section{Post-radiation biopsy findings}

The median number of biopsy cores was 11 (IQR 10-12), with a median of four (IQR 3-7) positive cores (Table 2). Similar post-radiation biopsy characteristics were seen regardless of extent of treatment effect in highest-risk location except for total number of cores $(p=0.02)$ and number of cores with treatment effect $(p<0.001)$ prior to salvage prostatectomy.
At the time of the post-RT, pre-SRP biopsy, the majority of patients, $63(90 \%)$, had a low PSA level $(<10 \mathrm{ng} / \mathrm{ml})$, with two patients $(2.8 \%)$ with NTE having a PSA level between 10 and $20 \mathrm{ng} / \mathrm{ml}$ and one patient with NTE having a PSA of $48 \mathrm{ng} / \mathrm{ml}$. A Gleason score $>7$ was assigned in 38 (54\%) patients: 28 with NTE, six with PTE, and four with CTE on post-RT biopsy. Another 17 (30.9\%) patients had a Gleason score of 7 (one CTE, one PTE, 15 NTE). In 15 patients, a Gleason score could not be assigned because of radiation-related changes (11 CTE, two PTE, two NTE). The median time between initiation of RT and SRP was 5.8 years (IQR 3.8-8.3).

\section{Salvage radical prostatectomy findings}

Final pathology results for the 70 patients, categorized by the post-radiation biopsy result, are described in Table 3. Evidence of treatment effect in the benign gland was seen in $96 \%(67 / 70)$ of patients, and the two patients who had no evidence of treatment effect had had carcinoma with NTE on biopsy. In the SRP specimen, $68 \%$ (47/70) of patients had adenocarcinoma with NTE, $16 \%(11 / 70)$ of patients had adenocarcinoma with PTE, and 14\% (10/70) had adenocarcinoma with CTE. Among 16 patients with an isolated finding of CTE on post-radiation biopsy, 44\% (7/16) had carcinoma with NTE on final pathology, 18\% (3/16) had PTE, 25\% (4/16) had CTE, and $6.3 \%(1 / 16)$ had no tumour present. There were no significant differences with respect to pathological features between the extent of treatment effect in the highest-risk location.

\section{Clinical outcomes following salvage prostatectomy}

Table 4 summarizes the primary clinical outcomes overall and by the extent of treatment effect in the highest-risk location at the time of pre-salvage biopsy. At last followup, nine of the 70 patients (13\%) had died and 61 (87\%) were alive. The median followup time among survivors was 2.8 years (range 0.02-7.8). Two of the nine deaths were caused by prostate cancer. The median OS was 7.7 years (95\% confidence interval $[\mathrm{Cl}] 7.7$ years-N/A), and the five-year OS rate was $83 \%(95 \% \mathrm{Cl} 63-92)$. Further analysis of OS and CSS could not be performed due to low event rate.

Overall, at last followup, 39 (56\%) of the 70 patients had died and/or experienced BCR, 30 (42\%) were alive without $B C R$, and one (1\%) was alive with unknown status of recurrence. Four patients were excluded from recurrence and survival outcome analysis: two whose dates of death were unknown, one who was lost to followup, and one whose status of recurrence was unknown. The median RFS was 2.78 years $(95 \% \mathrm{Cl} 0.81-5.43)$ and the five-year RFS rate was $37 \%$ (95\% Cl 22-52). Fig. 2 shows the Kaplan-Meier estimates for RFS by treatment effect extent at the highest-risk location at the time of pre-salvage biopsy $(p=0.12)$. There was no significant difference between the groups. 
Metcalfe et al.

\begin{tabular}{|c|c|c|c|c|c|}
\hline Characteristic & $\begin{array}{l}\text { All patients } \\
(n=70)\end{array}$ & $\begin{array}{c}\text { CTE } \\
(n=16)\end{array}$ & $\begin{array}{l}\text { PTE } \\
(n=9)\end{array}$ & $\begin{array}{c}\text { NTE } \\
(\mathrm{n}=45)\end{array}$ & $\mathbf{p}$ \\
\hline Age at diagnosis, median years (IQR) & $61.06(54.38-64.56)$ & $62.38(57.87-64.05)$ & $60.12(54.3-65.61)$ & $60.98(53.73-64.56)$ & 0.64 \\
\hline BMI, median $\mathrm{g} / \mathrm{m}^{2}(\mathrm{IQR})$ & $29.66(26.14-33.95)$ & $31.78(23.62-36.21)$ & $28.63(27.25-29.84)$ & $29.67(26.14-33.95)$ & 0.96 \\
\hline Race/ethnicity, n (\%) & & & & & 0.33 \\
\hline White & $46(65.7)$ & $9(56.3)$ & $6(66.7)$ & $31(68.9)$ & \\
\hline Black & $15(21.4)$ & $4(25)$ & $2(22.2)$ & $9(20)$ & \\
\hline Hispanic & $7(10)$ & $2(12.5)$ & $0(0)$ & $5(11.1)$ & \\
\hline Asian & $1(1.4)$ & $1(6.3)$ & $0(0)$ & $0(0)$ & \\
\hline Arab/Middle Eastern & $1(1.4)$ & $0(0)$ & $1(11.1)$ & $0(0)$ & \\
\hline PSA at diagnosis, median ng/ml (IQR) $(n=63)$ & $5.95(4.7-11.9)$ & $5.88(4.65-12.7)$ & $9.95(6.8-28)$ & $5.9(4.4-7.7)$ & 0.07 \\
\hline PSA at diagnosis, $\mathrm{n}(\%)$ & & & & & 0.07 \\
\hline$<10$ & $47(67)$ & $11(68.8)$ & $4(50)$ & $32(82.1)$ & \\
\hline $10-20$ & $8(11.4)$ & $4(25)$ & $2(25)$ & $2(5.1)$ & \\
\hline$\geq 20$ & $8(11.4)$ & $1(6.3)$ & $2(25)$ & $5(12.8)$ & \\
\hline Unknown & 7 & 0 & 1 & 6 & \\
\hline Gleason grade at diagnosis, $\mathrm{n}(\%)$ & & & & & 0.52 \\
\hline$<7$ & $16(22.8)$ & $5(31.3)$ & $1(11.1)$ & $10(25)$ & \\
\hline 7 & $39(55)$ & $7(43.8)$ & $7(77.8)$ & $25(62.5)$ & \\
\hline$>7$ & $10(14.2)$ & $4(25)$ & $1(11.1)$ & $5(12.5)$ & \\
\hline Unknown & $5(7.1)$ & $0(0)$ & $0(0)$ & 5 & \\
\hline Clinical T stage, $\mathrm{n}(\%)$ & & & & & 0.27 \\
\hline cT1 & $43(61.4)$ & $9(64.3)$ & $4(44.4)$ & $30(66.7)$ & \\
\hline cT2 & $17(24.2)$ & $3(21.4)$ & $2(22.2)$ & $12(26.7)$ & \\
\hline cT3 & $8(11.4)$ & $2(14.3)$ & $3(33.3)$ & $3(6.7)$ & \\
\hline Unknown & 2 & 2 & 0 & 0 & \\
\hline Hormonal therapy with radiation, $\mathrm{n}(\%)$ & & & & & 0.24 \\
\hline Yes & $22(31.4)$ & $5(31.3)$ & $5(55.6)$ & $12(26.7)$ & \\
\hline No & $48(68.6)$ & $11(68.8)$ & $4(44.4)$ & $33(73.3)$ & \\
\hline $\begin{array}{l}\text { Chemotherapy with or adjuvant to radiation, } \\
\mathrm{n}(\%)\end{array}$ & & & & & 1.00 \\
\hline Yes & $2(2.9)$ & $0(0)$ & $0(0)$ & $2(4.4)$ & \\
\hline No & $67(95.7)$ & $16(100)$ & $8(100)$ & $43(95.6)$ & \\
\hline Unknown & 1 & 0 & 1 & 0 & \\
\hline Primary local therapy, $\mathrm{n}(\%)$ & & & & & 0.81 \\
\hline EBRT & $42(60)$ & $11(68.8)$ & $6(66.7)$ & $25(55.6)$ & \\
\hline Brachy & $14(20)$ & $4(25)$ & $1(11.1)$ & $9(20)$ & \\
\hline Proton & $6(8.6)$ & $0(0)$ & $1(11.1)$ & $5(11.1)$ & \\
\hline EBRT + brachy & $8(11.4)$ & $1(6.3)$ & $1(11.1)$ & $6(13.3)$ & \\
\hline Prior salvage therapy, $\mathrm{n}(\%)$ & & & & & 0.71 \\
\hline No & $66(94.3)$ & $16(100)$ & $8(88.9)$ & $42(93.3)$ & \\
\hline EBRT & $1(1.4)$ & $0(0)$ & $0(0)$ & $1(2.2)$ & \\
\hline Cryo & $2(2.9)$ & $0(0)$ & $1(11.1)$ & $1(2.2)$ & \\
\hline Chemo & $1(1.4)$ & $0(0)$ & $0(0)$ & $1(2.2)$ & \\
\hline $\begin{array}{l}\text { Time from treatment to PSA nadir, median } \\
\text { years (IQR) }(n=59)\end{array}$ & $1.92(0.92-2.92)$ & $0.92(0.08-2.92)$ & $1.92(0.92-2.42)$ & $1.92(0.92-1.92)$ & 0.16 \\
\hline $\begin{array}{l}\text { PSA nadir after treatment, median (IQR) } \\
(n=55)\end{array}$ & $0.46(0.23-1.1)$ & $0.4(0.32-1.4)$ & $0.5(0.18-0.9)$ & $0.5(0.23-1.2)$ & 0.83 \\
\hline
\end{tabular}


Salvage prostatectomy for post-RT carcinoma with treatment effect

\begin{tabular}{|c|c|c|c|c|c|}
\hline Characteristic & $\begin{array}{l}\text { All patients } \\
\quad(n=70)\end{array}$ & $\begin{array}{c}\text { CTE } \\
(n=16)\end{array}$ & $\begin{array}{l}\text { PTE } \\
(n=9)\end{array}$ & $\begin{array}{c}\text { NTE } \\
(n=45)\end{array}$ & p \\
\hline PSA level, median ng/ml (IQR) ( $n=66)$ & $3.35(2.1-6)$ & $3.3(2.2-6)$ & $1.7(1.3-5.2)$ & $3.4(2.4-6.8)$ & 0.27 \\
\hline PSA level, n (\%) & & & & & 1.00 \\
\hline$<10$ & $63(90)$ & $15(100)$ & $9(100)$ & 39 (92.9) & \\
\hline 10-20 & $2(2.8)$ & $0(0)$ & $0(0)$ & $2(4.8)$ & \\
\hline$\geq 20$ & $1(1.4)$ & $0(0)$ & $0(0)$ & $1(2.4)$ & \\
\hline Unknown & 4 & & & & \\
\hline Gleason grade, n (\%) & & & & & 0.51 \\
\hline 7 & $17(24.2)$ & $1(6.3)$ & $1(14.3)$ & $15(34.9)$ & \\
\hline$>7$ & $38(54)$ & $5(31.3)$ & $6(85.7)$ & $28(65.1)$ & \\
\hline Unknown & 15 & 10 & 3 & 2 & \\
\hline Time from treatment to SRP, median (IQR) & $5.76(3.79-8.25$ & $4.85(2.39-5.88)$ & $6.04(5.66-8.06$ & $6.84(4.23-9.18)$ & 0.11 \\
\hline Number of cores total, median (IQR) & $11(10-12)$ & $12(11-15)$ & $10(8-11)$ & $11(9-12)$ & 0.02 \\
\hline Number of positive cores, median (IQR) & $4(3-7)$ & $4(2.5-10)$ & $5(3-6)$ & $5(3-7)$ & 0.95 \\
\hline Number of cores with CTE, median (IQR) & $6(2-11)$ & $12(10.5-13)$ & $9(4-10)$ & $4(0-7)$ & $<0.001$ \\
\hline Number of cores with no tumour present, median (IQR) & $4(0-7)$ & $7(5-10)$ & $4(1-6)$ & $3(0-6)$ & \\
\hline $\begin{array}{l}\text { Number of cores with tumour present with CTE, median } \\
\text { (IQR) }\end{array}$ & $0(0-2)$ & $3(1.5-6)$ & $0(0-3)$ & $0(0-0)$ & \\
\hline $\begin{array}{l}\text { Number of cores with tumour present with PTE, median } \\
\text { (IQR) }\end{array}$ & $0(0-0)$ & $0(0-0)$ & $3(0-5)$ & $0(0-0)$ & \\
\hline $\begin{array}{l}\text { Number of cores with tumour present with NTE, median } \\
\text { (IQR) }\end{array}$ & $1(0-5)$ & $0(0-0)$ & $0(0-0)$ & $4(1-6)$ & \\
\hline
\end{tabular}

CTE: carcinoma with treatment effect; IQR: interquartile range; NTE: no treatment effect; PTE: partial treatment effect; PSA: prostate-specific antigen; SRP: salvage radical prostatectomy.

Table 5 presents the results of Cox proportional hazards models for RFS. On univariate analysis, the number of positive cores $(p=0.01)$ and the Gleason grade $(p=0.03)$ for the pre-SRP biopsy were significantly associated with RFS. Both covariates were included in the multivariate analysis and remained significant; patients with more positive cores and those with higher Gleason grade for the pre-SRP biopsy were at higher risk of death or BCR.

\section{Discussion}

Our study is the first to our knowledge to assess SRP specimen pathology in patients who were found to have CTE or PTE in post-radiation biopsies performed for cause. More than $50 \%$ of these patients had viable cancer showing no treatment effect in the SRP specimen. Advanced pathological features were common in these patients, including Gleason grade 8 or higher $(60 \%)$, seminal vesicle involvement $(44 \%)$, positive surgical margins (28\%), and positive lymph nodes $(20 \%)$. Furthermore, the presence or absence of treatment effect did not predict RFS or time to metastasis. We found that treatment effect was not predictive of final pathological outcome at radical prostatectomy. There was no statistical association between the pre-SRP biopsy when classified by CTE, PTE, or NTE and the final pathology in terms of stage $(p=0.29)$, margin status $(p=0.13)$, Gleason grade $(p=0.11)$, presence of treatment effect in highest-risk location $(p=0.22)$, or presence of treatment effect in benign glands $(p=1.0)$.
Most of the information previously available on the significance of post-radiation biopsies comes from studies of patients undergoing routine biopsies after radiation. Patients with viable cancer (NTE) on a routine biopsy 24-38 months after radiation have between 3 and 7.5 times the risk of death from prostate cancer as do patients with negative biopsies (with a higher risk of death if the biopsy is positive after combined hormonal therapy and radiation). ${ }^{1-3}$ Given the established biological threat of this histological pattern of prostate cancer, the finding of viable cancer (NTE) in more than $50 \%$ of SRP specimens whose for-cause biopsy showed CTE or PTE is significant. The patients in our study underwent for-cause biopsies and therefore may be different from patients undergoing routine biopsies after radiation. In particular, our patients may be enriched for NTE cancers because of their biochemical relapse.

The significance of CTE or PTE in routine biopsies has been inconsistent. Crook et al looked at post-biopsy results in 205 men and demonstrated that a positive biopsy was predictive of subsequent metastasis and prostate cancer-specific death. ${ }^{9}$ At seven years' followup, only $66 \%$ of the 33 patients with severe treatment effect were biochemically diseasefree, which was not statistically different from the rate for patients with a negative biopsy. Zelefsky et al demonstrated that 10 -year PSA relapse-free survival was $59 \%$ for patients with negative biopsies, compared to $49 \%$ for those with severe treatment effect and only 3\% for those with NTE on biopsy. ${ }^{10}$ Although the patients with severe treatment effect 
Metcalfe et al.

\begin{tabular}{|c|c|c|c|c|c|}
\hline Characteristic & $\begin{array}{l}\text { All patients } \\
(n=70)\end{array}$ & $\begin{array}{c}\text { CTE } \\
(n=16)\end{array}$ & $\begin{array}{l}\text { PTE } \\
(n=9)\end{array}$ & $\begin{array}{c}\text { NTE } \\
(n=45)\end{array}$ & p \\
\hline Pathological stage at SRP, $\mathrm{n}(\%)$ & & & & & 0.29 \\
\hline рT0 & $1(1.4)$ & $1(6.3)$ & $0(0)$ & $0(0)$ & \\
\hline pT2 & $26(37.1)$ & 7 (43.8) & $2(22.2)$ & 17 (37.8) & \\
\hline pT3 & $41(58.6)$ & 7 (43.8) & 7 (77.8) & $27(60)$ & \\
\hline pT4 & $1(1.4)$ & $0(0)$ & $0(0)$ & $1(2.2)$ & \\
\hline $\mathrm{pIN}$ & $1(1.4)$ & $1(6.3)$ & $0(0)$ & $0(0)$ & \\
\hline Positive margins, $\mathrm{n}(\%)$ & & & & & 0.13 \\
\hline Yes & $14(20)$ & $3(18.8)$ & $4(44.4)$ & $7(15.6)$ & \\
\hline No & $56(80)$ & $13(81.3)$ & $5(55.6)$ & $38(84.4)$ & \\
\hline Seminal vesicle involvement, $\mathrm{n}(\%)$ & & & & & 0.93 \\
\hline None & $38(54.3)$ & $10(62.5)$ & $4(44.4)$ & $24(53.3)$ & \\
\hline Unilateral & 9 (12.9) & $2(12.5)$ & $1(11.1)$ & $6(13.3)$ & \\
\hline Bilateral & $23(32.9)$ & $4(25)$ & $4(44.4)$ & $15(33.3)$ & \\
\hline Gleason grade for SRP specimen, $\mathrm{n}(\%)$ & & & & & 0.11 \\
\hline 7 & $18(25.7)$ & $1(11.1)$ & $1(12.5)$ & $16(43.2)$ & \\
\hline $8-10$ & $36(67)$ & $8(88.9)$ & 7 (87.5) & $21(56.8)$ & \\
\hline Unknown & 16 & 7 & 1 & 8 & \\
\hline Treatment effect in highest-risk foci at SRP, $\mathrm{n}(\%)$ & & & & & 0.22 \\
\hline No & $1(1.4)$ & $1(6.7)$ & $0(0)$ & $0(0)$ & \\
\hline CTE & $10(14.5)$ & $4(26.7)$ & $1(11.1)$ & $5(11.1)$ & \\
\hline PTE & $11(15.9)$ & $3(20)$ & $2(22.2)$ & $6(13.3)$ & \\
\hline NTE & $47(68.1)$ & $7(43.7)$ & $6(66.7)$ & $34(75.6)$ & \\
\hline Unknown & 1 & 1 & 0 & 0 & \\
\hline Treatment effect in benign gland at SRP, $\mathrm{n}(\%)$ & & & & & 1.00 \\
\hline Yes & $67(97.1)$ & $15(100)$ & $9(100)$ & $43(95.6)$ & \\
\hline No & $2(2.9)$ & $0(0)$ & $0(0)$ & $2(4.4)$ & \\
\hline Unknown & 1 & 1 & 0 & 0 & \\
\hline Positive nodes, n (\%) & & & & & 0.96 \\
\hline No & $56(80)$ & $13(71)$ & $7(78)$ & $36(80)$ & \\
\hline Yes & $14(20)$ & $3(19)$ & $2(22)$ & $9(20)$ & \\
\hline Total number of nodes removed, median (IQR) & $12(9-16)$ & $11(8.5-16)$ & $10(10-15)$ & $12(9-16)$ & 0.85 \\
\hline
\end{tabular}

CTE: carcinoma with treatment effect; IQR: interquartile range; NTE: no treatment effect; PTE: partial treatment effect; SRP: salvage radical prostatectomy.

had lower 10-year PSA survival rates, this was not statistically significant and did not correlate with metastasis-free survival or CSS. Vance et al looked at the clinical outcome of patients based on routine biopsy at two years as stratified by those with negative (no cancer), atypical/suspicious cells (not diagnostic of carcinoma), CTE, and NTE. ${ }^{11}$ Patients with atypical cells or CTE had intermediate risk for BCR that was higher than that for patients with negative biopsies, but not as high as the risk for patients with NTE. ${ }^{11}$ When taken together, the slightly lower biochemical disease-free survival for patients with CTE in some studies suggests that a subset of these patients harbor significant disease. Our results support this hypothesis in that over $50 \%$ of patients with CTE on for-cause biopsy had viable cancer (NTE). It is also important to note that all of the studies of CTE in routine biopsies after radiation have followup of 10 years or less.
Localized prostate cancer has a 20-year natural history, and it is conceivable that with longer followup, more patients with CTE on routine post-radiation biopsy may develop BCR.

Our study had stringent entry criteria. All patients had forcause biopsies. The majority of patients (94\%) met ASTRO criteria for PSA failure following radiation. Only those with adequate descriptions of treatment effect in post-radiation prostate adenocarcinoma were included. Between the three categories into which we divided the post-radiation biopsies (CTE, PTE, and NTE), the baseline patient demographics were homogeneous. The majority of patients had D'Amico classification low- or intermediate-risk disease, which was localized to the prostate prior to radiation. Following radiation, the majority still had PSA $<10 \mathrm{ng} / \mathrm{ml}(90 \%)$; however, more patients had high-risk disease by Gleason score $54 \%$ had a Gleason grade $>7$ after RT, vs. $14 \%$ at initial diagno- 


\begin{tabular}{|c|c|c|c|c|}
\hline Characteristic & $\begin{array}{l}\text { All patients } \\
(n=70)\end{array}$ & $\begin{array}{c}\text { CTE } \\
(n=16)\end{array}$ & $\begin{array}{l}\text { PTE } \\
(\mathrm{n}=9)\end{array}$ & $\begin{array}{c}\text { NTE } \\
(n=45)\end{array}$ \\
\hline Post-SRP PSA, median (IQR) & $0.01(0.01,0.1)$ & $0.01(0.01,0.45)$ & $0.01(0.01,1.6)$ & $0.01(0.01,0.1)$ \\
\hline Biochemical recurrence, $\mathrm{n}(\%)$ & $35(51.5)$ & $11(68.8)$ & $3 / 7$ (42.9) & $21(46.7)$ \\
\hline Time to biochemical recurrence, median years (IQR) & $0.44(0.11,1.70)$ & $0.40(0.22,1.52)$ & $0.09(0.07,2.78)$ & $0.62(0.05,1.90)$ \\
\hline \multicolumn{5}{|l|}{ Hormonal therapy, n (\%) } \\
\hline Pre-SRP & $18(26)$ & $6(37.5)$ & $2(22.2)$ & $10(22)$ \\
\hline Post-SRP for biochemical recurrence & $13(18.8)$ & $4(25)$ & $1(11.1)$ & $8(17.8)$ \\
\hline Development of androgen independence, $\mathrm{n}(\%)$ & $11(16.2)$ & $5 / 15$ (33.3) & $2 / 8(25)$ & $4(8.9)$ \\
\hline Time to androgen independence, median years (IQR) & $2.03(0.89,3.56)$ & $0.91(0.89,2.03)$ & $3.51(3.46,3.56)$ & $1.72(0.88,3.34)$ \\
\hline Presence of mets after SRP, n (\%) & $8(11.8)$ & $4 / 15(26.7)$ & $1 / 8(12.5)$ & $3(6.7)$ \\
\hline Time to mets, median years (IQR) & $3.03(2.45,4.47)$ & $3.20(1.96,4.44)$ & $4.77(4.47,5.07)$ & $2.45(0.98,2.86)$ \\
\hline Followup time, median years (range) & $2.79(0.02,7.76)$ & $2.98(0.74,7.76)$ & $2.45(0.02,6.00)$ & $2.67(0.13,7.72)$ \\
\hline \multicolumn{5}{|l|}{ Status at last followup, n (\%) } \\
\hline Dead & $9(12.9)$ & $2(12.5)$ & $2(22.2)$ & $5(11.1)$ \\
\hline Alive & $61(87.1)$ & $14(87.5)$ & $7(77.8)$ & $40(88.9)$ \\
\hline \multicolumn{5}{|l|}{ Current status, n (\%) } \\
\hline NED & $23(33.3)$ & $2(12.5)$ & $3(33.3)$ & $18(40)$ \\
\hline EDR & $28(40.5)$ & $8(50)$ & $4(44.4)$ & $16(35.6)$ \\
\hline ED & $18(40)$ & $6(37.5)$ & $1(11.1)$ & $11(24.4)$ \\
\hline \multicolumn{5}{|l|}{ Prostate cancer-caused death, n (\%) } \\
\hline Prostate & 2 & 0 & 1 & 1 \\
\hline Other & 4 & 1 & 0 & 3 \\
\hline Unknown & 3 & 1 & 1 & 1 \\
\hline RFS, median $(95 \% \mathrm{Cl})$ & $2.78(0.84,5.43)$ & $0.51(0.22,2.35)$ & $2.78(0.07,2.78)$ & $4.95(0.95,7.08)$ \\
\hline
\end{tabular}

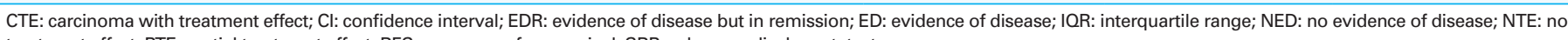
treatment effect; PTE: partial treatment effect; RFS: recurrence-free survival; SRP: salvage radical prostatectomy.

sis). These clinical features are typical for a post-radiation salvage prostatectomy cohort.

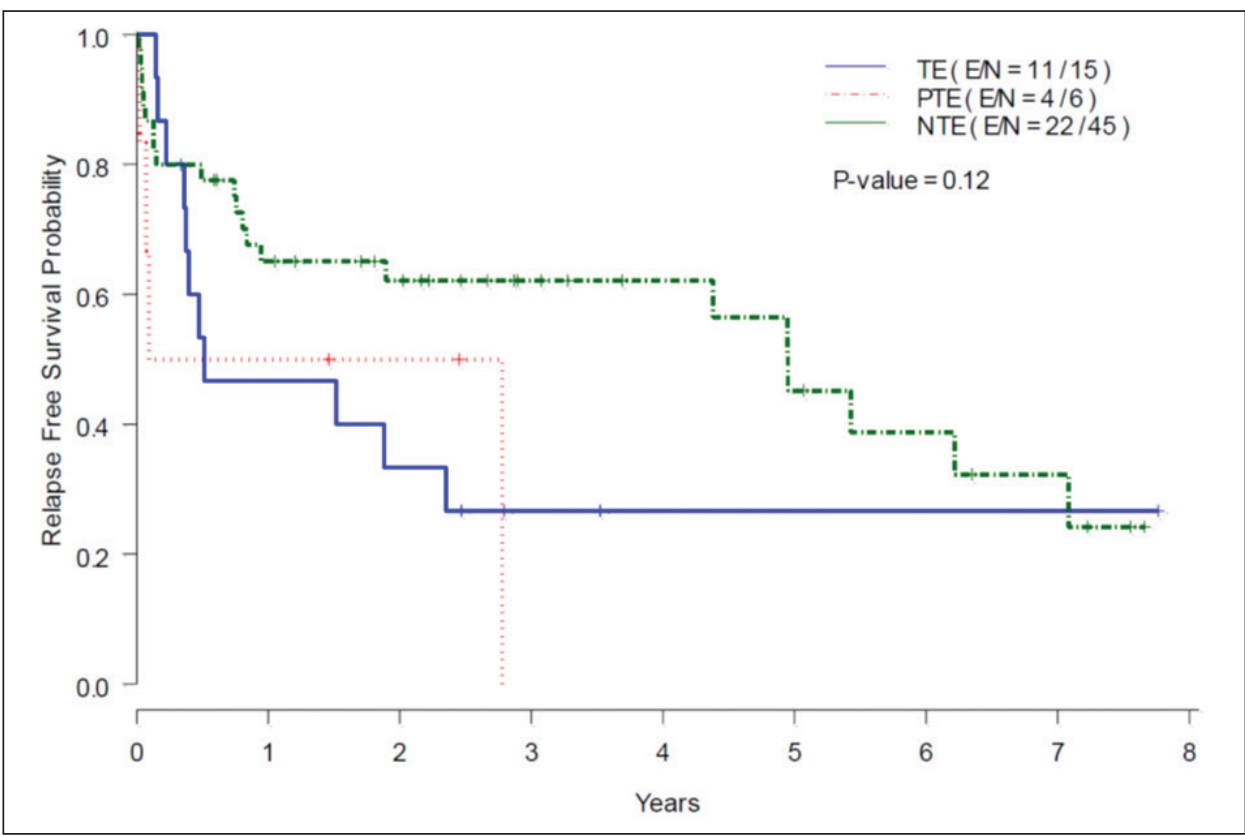

Fig. 2. Kaplan-Meier estimates for recurrence-free survival by treatment effect in highest-risk location for patients with carcinoma with treatment effect, carcinoma with partial treatment effect and carcinoma with no treatment effect at the time of pre-salvage radical prostatectomy biopsy.
There are inherent weaknesses in this retrospective review. All of our patients were treated with SRP. We are lacking a comparative group of patients who had CTE who did not undergo SRP. Such a comparison group would help establish the natural history of BCR with CTE on a for-cause biopsy without salvage local therapy. Future research should include evaluating the long-term clinical outcome of CTE in terms of biochemical, progression-free, and overall survival. Also, molecular and immunohistochemical studies may reveal markers of progression in CTE patients.

\section{Conclusion}

Patients undergoing SRP for CTE or PTE demonstrated in a for-cause biopsy after RT had pathological evidence of viable, untreated cancer in more than $50 \%$ of cases and were at significant risk of adverse pathological features. Patients with CTE may therefore benefit from SRP. 
Metcalfe et al.

\begin{tabular}{|c|c|c|c|}
\hline Characteristic & $\begin{array}{l}\text { Events/ } \\
\text { total }\end{array}$ & HR (95\% Cl) & $\mathbf{p}^{*}$ \\
\hline \multicolumn{4}{|l|}{ Univariate } \\
\hline Age at diagnosis & $37 / 66$ & $1.00(0.95,1.05)$ & 0.95 \\
\hline $\mathrm{BMI}$ & $37 / 66$ & $1.05(0.99,1.11)$ & 0.10 \\
\hline Race: non-White vs. White & $37 / 66$ & $1.19(0.60,2.38)$ & 0.62 \\
\hline Gleason grade at diagnosis & & & 0.22 \\
\hline 7 vs. $>7$ & $33 / 61$ & $0.64(0.25,1.62)$ & \\
\hline$<7$ vs. $>7$ & & $0.36(0.11,1.14)$ & \\
\hline Clinical T stage: cT1 vs. cT2/cT3 & $36 / 64$ & $0.60(0.31,1.17)$ & 0.13 \\
\hline $\begin{array}{l}\text { Hormonal therapy with } \\
\text { radiation: yes vs. no }\end{array}$ & $37 / 66$ & $1.48(0.75,2.92)$ & 0.26 \\
\hline PSA at diagnosis (log) & $32 / 60$ & $1.11(0.75,1.63)$ & 0.61 \\
\hline $\begin{array}{l}\text { Time from treatment to nadir } \\
\text { (log) }\end{array}$ & $30 / 55$ & $0.95(0.72,1.25)$ & 0.71 \\
\hline PSA nadir after treatment (log) & $27 / 51$ & $0.98(0.66,1.46)$ & 0.91 \\
\hline $\begin{array}{l}\text { Time from treatment to salvage } \\
\text { (log) }\end{array}$ & $37 / 66$ & $1.42(0.85,2.37)$ & 0.18 \\
\hline PSA prior to salvage (log) & $35 / 62$ & $1.16(0.71,1.88)$ & 0.55 \\
\hline $\begin{array}{l}\text { Pre-SRP biopsy, number of } \\
\text { cores total }\end{array}$ & $37 / 66$ & $1.05(0.93,1.18)$ & 0.42 \\
\hline $\begin{array}{l}\text { Pre-SRP biopsy, number of } \\
\text { positive cores }\end{array}$ & $37 / 66$ & $1.12(1.03,1.22)$ & 0.01 \\
\hline $\begin{array}{l}\text { Pre-SRP biopsy, number of } \\
\text { cores with TE }\end{array}$ & $37 / 66$ & $1.02(0.95,1.09)$ & 0.57 \\
\hline $\begin{array}{l}\text { Gleason grade prior to SRP: } 7 \\
\text { vs. }>7\end{array}$ & $28 / 53$ & $0.34(0.13,0.92)$ & 0.03 \\
\hline $\begin{array}{l}\text { Treatment effect in highest-risk } \\
\text { location }\end{array}$ & & & 0.13 \\
\hline CTE vs. NTE & $37 / 66$ & $1.83(0.88,3.82)$ & \\
\hline PTE vs. NTE & & $2.36(0.80,6.97)$ & \\
\hline \multicolumn{4}{|l|}{ Multivariate } \\
\hline $\begin{array}{l}\text { Pre-salvage biopsy, number of } \\
\text { positive cores }\end{array}$ & $28 / 53$ & $1.11(1.00,1.22)$ & 0.05 \\
\hline $\begin{array}{l}\text { Gleason grade prior to SRP: } 7 \\
\text { vs. }>7\end{array}$ & & $0.38(0.14,1.02)$ & 0.05 \\
\hline
\end{tabular}

Competing interests: The authors report no competing personal or financial interests.
Acknowledgment: This study was supported by the U.S. National Institutes of Health/National Cancer Institute under award number P30CA016672 (used the Biostatistics Resource Group and (linical Trials Support Resource).

This paper has been peer-reviewed.

\section{References}

1. Crook J, Malone S, Perry G, et al. Post-radiotherapy prostate biopsies: What do they really mean? Results for 498 patients. Int J Radiat Oncol Biol Phys 2000;4:355-67. https://doi.org/10.1016/ S0360-3016(00)00637-4

2. Crook JM, Bahadur YA, Robertson SJ, et al. Evaluation of radiation effect, tumour differentiation, and prostate-specific antigen staining in sequential prostate biopsies after external beam radiotherapy for patients with prostate carcinoma. Cancer 1997;79:81-9. https://doi.org/10.1002/(SICI) 10970142(19970101)79:1<81::AID-CNCR12>3.0.C0;2-2

3. Crook JM, Perry GA, Robertson $S$, et al. Routine prostate biopsies following radiotherapy for prostate cancer: Results for 226 patients. Urology 1995;45:624-31; discussion 31-2. https://doi.org/10.1016/ S0090-4295(99) 80054-5

4. Brawer MK, Peehl DM, Stamey TA, et al. Keratin immunoreactivity in the benign and neoplastic human prostate. Cancer Res 1985;45:3663-7.

5. Brawer MK, Nagle RB, Pitts W, et al. Keratin immunoreactivity as an aid to the diagnosis of persistent adenocarcinoma in irradiated human prostates. Cancer 1989;63:454-60. https://doi.org/10.1002/10970142(19890201)63:3<454::AID-CNCR2820630311>3.0.C0;2-E

6. Roach M 3rd, Hanks G, Thames $\mathrm{H} \mathrm{Jr}$, et al. Defining biochemical failure following radiotherapy with or without hormonal therapy in men with clinically localized prostate cancer: Recommendations of the RTOG-ASTRO Phoenix Consensus Conference. Int I Radiat Oncol Biol Phys 2006;65:965-74. https://doi.org/10.1016/i.ijrobp.2006.04.029

7. Kaplan EL, Meier P. Non-parametric estimator from incomplete observations. J Am Stat Assoc 1958;53:45781. https://doi.org/10.1080/01621459.1958.10501452

8. Cox HL Jr. Cox DR. Regression models and life tables. J R Stat Soc Series B Stat Methodol 1972;34:187220.

9. Crook JM, Malone S, Perry G, et al. Twenty-four-month post-radiation prostate biopsies are strongly predictive of seven-year disease-free survival: Results from a Canadian randomized trial. Cancer 2009;115:6739. hitps://doi.org/10.1002/cncr.24020

10. Zelefsky MJ, Reuter VE, Fuks Z, et al. Influence of local tumour control on distant metastases and cancer-related mortality after external beam radiotherapy for prostate cancer. J Urol 2008; 179:1368-73; discussion 73. htrps://doi.org/10.1016/i.juro.2007.11.063

11. Vance W, Tucker SL, de Crevoisier R, et al. The predictive value of two-year post-treatment biopsy after prostate cancer radiotherapy for eventual biochemical outcome. Int J Radiat Oncol Biol Phys 2007;67:82833. https://doi.org/10.1016/i.ijrobp.2006.09.02

Correspondence: Dr. Michael J. Metcalfe, Department of Urology, University of Texas MD Anderson Cancer Centre, Houston, TX, United States; michaelmetcalfe5@gmail.com 